\title{
Dominantly Inherited Ataxias in Portugal
}

\author{
L. Cunha, A. Gonçalves, M. Dinis, C. Oliveira, M. Ferro, A. Vicente*, \\ M. Roy and A. Barbeau**
}

\begin{abstract}
We analysed the clinical features of 82 patients with dominantly inherited ataxia in a cohort survey. All patients fulfilled the diagnostic criteria for Machado-Joseph disease. The mean age of onset of symptoms was 39.8 ( \pm 12.5) years and the duration of the disease was $9.2( \pm 6.7)$ years. Ataxia, peripheral neuropathy, and fasciculation scores correlated with age of onset and duration of disease. Upper motor neuron scores failed to correlate with age of onset. In a follow-up study we analysed the clinical data of 46 patients two years after the first examination. A paired ttest was used to compare differences between observations. The results are in agreement with those of the cross-section in time, suggesting a deterioration of the symptoms with the evolution of the disease. We conclude that dynamic definition of the disease according to age of onset and duration of symptoms is preferable to subdivision into classical types.
\end{abstract}

RÉSUMÉ: Les ataxies d'hérédités dominantes au Portugal. Nous avons analysé dans un étude prospective, les caracteristiques cliniques de 82 patients atteints d'ataxie dominante. Tous les malades présentaient un cadre clinique suggestif de maladie de Machado-Joseph. L'âge moyen de début des symptômes était de $39.8( \pm 12.5)$ ans et la durée de $9.2( \pm 6.7)$ ans. Il y avait une corrélation positive des scores de l'ataxie, de l'atteinte périphérique et des fasciculations avec l'âge de début et la durée de la maladie. La correlation entre le score pyramidal et l'âge de début de l'affection était négative. Nous avons comparé statistiquement les symptômes chez 46 patients dans un étude de surveillance de deux ans. Les résultats sont d'accord avec les données des études transversales, montrant une détérioration des symptômes avec l'évolution de la maladie. Nous concluons que la définition dynamique de la maladie est préférable aux subdivisions dans des types cliniques.

Can.J. Neurol. Sci. 1988: 15: 397-401

Despite several attempts to develop a classification of the dominantly inherited ataxias, ${ }^{1-4}$ classification of these disorders still presents many problems. The main difficulty seems to be the marked intra- and interfamilial variation that is evident not only in the distribution of pathological lesions, but also in the clinical signs. This variation is responsible for the inconsistency of any classification based on pathological or clinical criteria and leads to frequent overlap among the proposed groups and disagreement regarding classification of individual families. 4,5 To overcome this difficulty Koeppen et $a^{6}$ proposed that hereditary ataxia should be subdivided only by mode of genetic transmission, i.e., either autosomal dominant or autosomal recessive. This view is suitable for the study of causes of heterogeneity, and was followed in the present study.

Analysis of dominant ataxias in Portugal must also take into account Machado-Joseph disease. This disorder was first described in families of Azorean origin in the United States $7-11$ and was later observed in the Azores 12.13 in continental Portugal 14 and also in families with no known Portuguese ancestry. ${ }^{15-18}$ In Machado-Joseph disease, variation in the clinical findings was remarkable (Table 1), and most of the signs were previously described in other dominant ataxias, mainly in olivo-ponto-cerebellar atrophy (OPCA). Apart from some families with OPCA where optic atrophy, 19-23 pigmentary retinopathy 3.,.24-28 and dementia 3 ,4,23,29-31 were observed, OPCA and Machado-Joseph disease have many clinical features in common. Similar findings have also been described in disorders labelled as dentato-rubro-pallido-luysian atrophy, ${ }^{16}$ spinopontine degeneration ${ }^{22,32}$ and spastic ataxia. ${ }^{33}$

The only consistent argument in favour of a distinction between OPCA and Machado-Joseph disease is derived from pathological findings: in Machado-Joseph disease the cerebellar cortex and olivary nuclei are spared.9.34 Nevertheless, there is considerable overlap in the neuropathology of both diseases. In this paper we describe patients with dominantly inherited ataxia from the Azores and continental Portugal.

\section{Materials AND MethodS}

Eighty-two patients suffering from dominant ataxia were examined in the Azores and in continental Portugal. The clinical features were documented in a protocol incorporating a total of 81 items adapted from the scale developed by Pourcher and Barbeau. ${ }^{35}$ These were grouped into 7 categories: 1) Ataxia

From The Clinica Neurologica - HUC, Coimbra, Portugal (Drs. Cunha, Gonçalves, Dinis, Oliveira, Ferro, Vicente*) and The Clinical Research Institute of Montreal (Drs. Roy, Barbeau**)

Received December 16, 1986. Accepted in final form July 10, 1988

*Deceased December 1987

**Deceased March 1986

Reprint requests to: Dr. Luis Cunha, Hospitais da Universidade Coimbra, Clinica Neurológica, 3000 Coimbra, Portugal 
Table 1: Degree of Clinical Signs in Previously Reported Series of Machado-Joseph Disease and OPCA (Severe ++; Moderate +; Mild \pm ; Normal or Absent -).

\begin{tabular}{|c|c|c|c|c|c|c|c|}
\hline & \multicolumn{2}{|l|}{ OPCA } & \multicolumn{4}{|c|}{ Machado-Joseph Disease } & \multirow[b]{2}{*}{ Barbeau et al $^{36}$} \\
\hline & Berciano $^{5}$ & Nakano et al 7 & $\begin{array}{c}\text { Woods and } \\
\text { Schaumburg8 }\end{array}$ & Rosenberg et al ${ }^{9}$ & Romanul et al ${ }^{11}$ & $\begin{array}{l}\text { Coutinho and } \\
\text { Andrade }\end{array}$ & \\
\hline Ataxia & ++ & ++ & ++ & + & ++ & ++ & ++ \\
\hline Hyperreflexia & + & \pm & ++ & ++ & + & + & + \\
\hline Spasticity & + & - & + & ++ & - & + & + \\
\hline Hyporreflexia & \pm & $+t$ & - & - & + & + & + \\
\hline Atrophy & + & ++ & + & - & ++ & + & + \\
\hline Fasciculations & \pm & + & $?$ & + & ++ & + & + \\
\hline \multicolumn{8}{|l|}{ Impaired Vibration } \\
\hline Sense & \pm & + & \pm & - & ++ & \pm & ++ \\
\hline Parkinsonism & \pm & - & ++ & ++ & + & + & - \\
\hline Dystonia & \pm & - & - & + & - & + & - \\
\hline Ophthalmoplegia & + & $?$ & + & ++ & ++ & ++ & ++ \\
\hline Optic Atrophy & \pm & - & - & \pm & - & - & - \\
\hline \multicolumn{8}{|l|}{ Pigmentary } \\
\hline Retinopathy & \pm & - & - & - & - & - & - \\
\hline Dementia & \pm & - & - & - & - & - & - \\
\hline
\end{tabular}

score, including gait ataxia, Romberg sign, and limb incoordination (maximum 16); 2) Upper motor neuron (UMN) score, including spasticity, hyperreflexia, clonus and Babinski sign (maximum 16); 3) Peripheral score, including decreased tendon reflexes and atrophy (maximum 16); 4) Fasciculation score (maximum 3); 5) Parkinsonian score, including cogwheel rigidity and bradykinesia (maximum 12); 6) Ophthalmoplegia score, (maximum 3); and 7) Vibration sense score (maximum 3). Neurological examinations were recorded on videotape and the scores were also re-evaluated retrospectively.

The patients belonged to 21 families from the Azores which included the large Sousa family in Flores, and 7 families living in continental Portugal. Two years later we re-examined 46 patients to determine the evolution of the disorders (Table 2). Statistical analysis was made using correlation matrix between clinical features, age of onset, and duration of disease. For comparison with the follow-up study, the paired t-test was used.

\section{Results}

Ataxia of gait was the initial complaint in 66 patients $(80.5 \%)$. The others presented diplopia, tremor, pain, or vertigo as the first symptom. All patients had ataxia at the time of the first examination, although its severity differed from case to

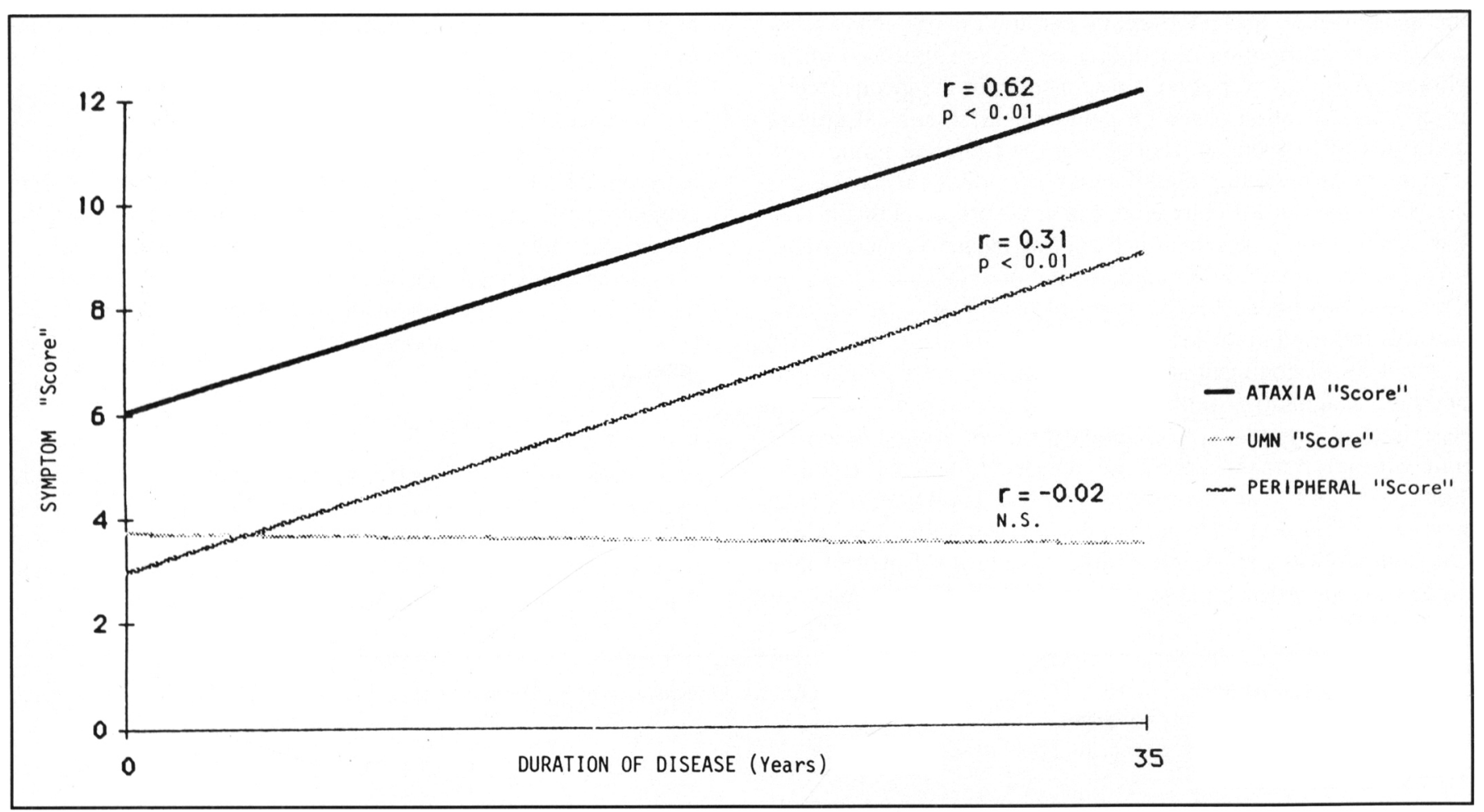

Figure I - Dominant Ataxias: Correlation between clinical features and duration of disease at first examination (82 patients). 


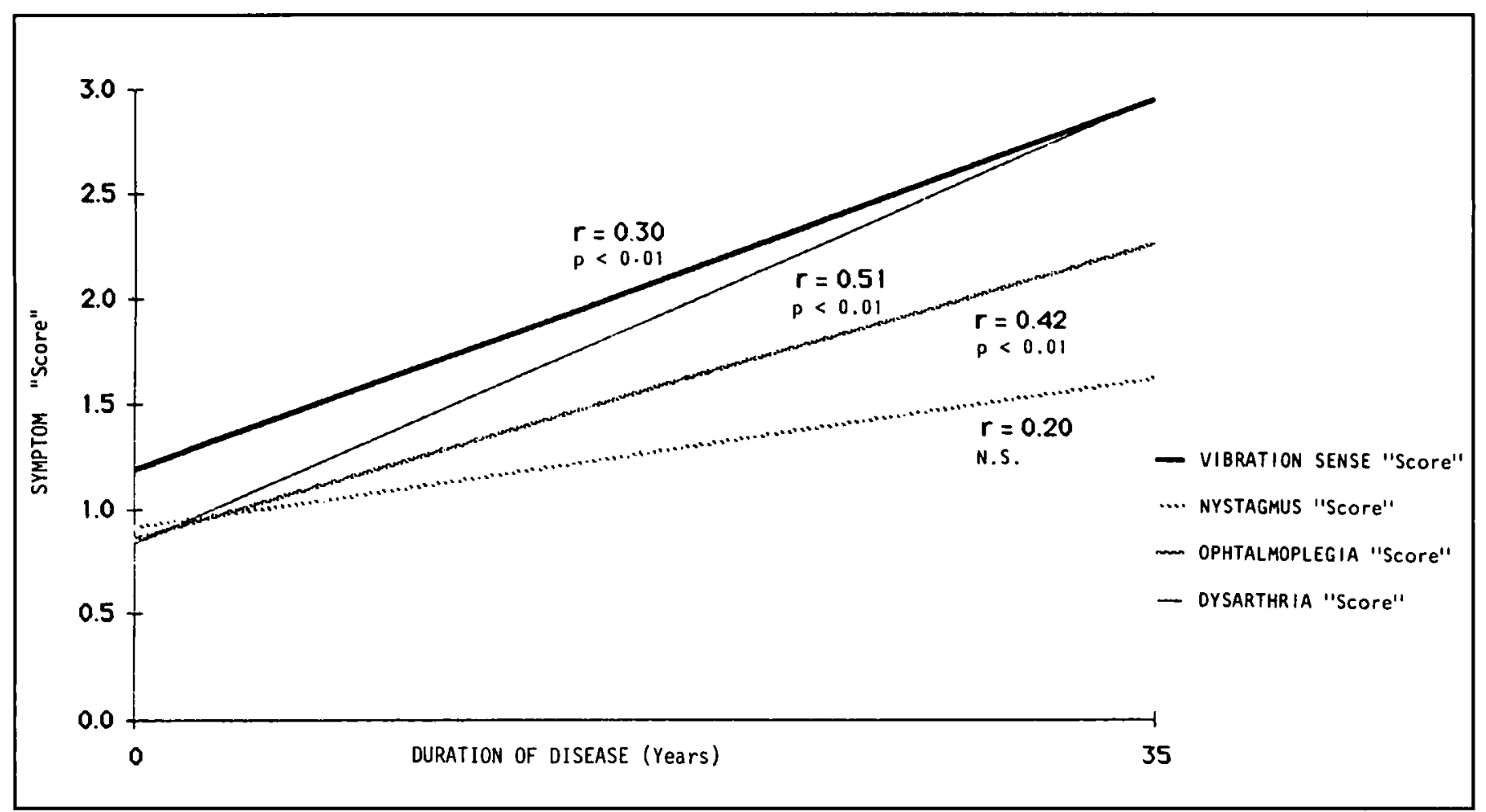

Figure 2 -Dominant Ataxias: Correlation between clinical features and duration of disease at first examination (82 patients).

\begin{tabular}{|c|c|c|c|c|c|c|c|}
\hline & \multicolumn{3}{|c|}{ 1st Observation } & \multicolumn{3}{|c|}{ 2nd Observation } & \multirow{2}{*}{$\underset{\text { Global }}{\mathrm{P}}$} \\
\hline & Male & Female & Global & Male & Female & Global & \\
\hline Duration of Disease & $8.5 \pm 4.5$ & $6.7 \pm 4.9$ & $7.5 \pm 4.8$ & & & & \\
\hline Ataxia & $9.2 \pm 2.4$ & $7.3 \pm 3.3$ & $8.2 \pm 3.1$ & $12.2 \pm 1.9$ & $10.8 \pm 2.4$ & $11.4 \pm 2.3$ & $<0.001$ \\
\hline UMN Signs & $3.8 \pm 4.0$ & $2.7 \pm 4.0$ & $3.2 \pm 4.0$ & $5.0 \pm 4.2$ & $3.9 \pm 2.1$ & $4.4 \pm 3.3$ & $<0.02$ \\
\hline Peripheral Signs & $6.4 \pm 4.0$ & $3.5 \pm 3.4$ & $4.9 \pm 4.0$ & $8.8 \pm 4.0$ & $6.8 \pm 4.3$ & $7.7 \pm 4.3$ & $<0.001$ \\
\hline $\begin{array}{l}\text { Sense } \\
\text { Muscle Atrophy }\end{array}$ & $\begin{array}{l}2.2 \pm 0.7 \\
3.4 \pm 2.4\end{array}$ & $\begin{array}{l}1.7 \pm 0.8 \\
1.4 \pm 1.9\end{array}$ & $\begin{array}{l}1.9 \pm 0.8 \\
2.3 \pm 2.4\end{array}$ & $\begin{array}{l}2.4 \pm 0.5 \\
4.9 \pm 2.3\end{array}$ & $\begin{array}{l}2.2 \pm 0.9 \\
3.4 \pm 2.7\end{array}$ & $\begin{array}{l}2.3 \pm 0.1 \\
4.1 \pm 2.7\end{array}$ & $\begin{array}{l}<0.01 \\
<0.001\end{array}$ \\
\hline Fasciculations & $2.3 \pm 1.4$ & $1.3 \pm 1.6$ & $1.7 \pm 1.6$ & $2.7 \pm 1.6$ & $1.7 \pm 1.4$ & $2.3 \pm 1.6$ & $<0.01$ \\
\hline Global Score & $29.0 \pm 4.9$ & $20.8 \pm 9.3$ & $24.6 \pm 8.6$ & $39.6 \pm 4.4$ & $33.1 \pm 7.4$ & $36.1 \pm 6.9$ & $<0.001$ \\
\hline
\end{tabular}

case. In 33 patients gait ataxia was so severe that walking without support was impossible.

Incoordination also was present in the upper limbs of 78 patients, usually of less severe degree than that found in the lower limbs. The global ataxic score was related to the duration of the disease $(p<0.01)$.

UMN signs were present in 67 patients $(81.7 \%)$ and were related to age of onset $(p<0.01)$, being more prominent at younger ages. Babinski sign $(69.5 \%)$ and hyperreflexia $(55 \%)$ were the most common. Spasticity was present in 19 patients and was more severe in the lower limbs. Ten patients had ankle clonus.

Peripheral signs were present in $83 \%$ of the cases and were severe in 32 percent. Atrophy of muscle occurred in 56 patients $(68 \%)$ and could be observed more often in the face (masseter and temporal muscles), arms (biceps and triceps), forearms, hands (interosseus), legs (peroneal) and feet. It was frequently marked just above the elbow and knee joints. This atrophy predominated in proximal segments of 18 patients with a younger age of onset of symptoms. In patients with a later onset of disease, atrophy was evident or predominated in the distal extremities as well. Diminished or absent tendon reflexes also appeared late in the course of the disease, or if the onset was at an older age. Reflex depression occurred in 42 patients $(51 \%)$. Fasciculations were present in 53 patients $(64.6 \%)$ and were more evident in men. They were usually widespread and predominated in the peribuccal and periocular regions, and in muscles of the arm, forearm, hip, and legs. Sometimes they were observed only after muscular effort.

The majority of the patients $(87.7 \%$ ) had some degree of external ophthalmoplegia, generally of mild degree $(58.3 \%)$. It usually began with limitation of upward gaze. Later, ocular movements were impaired in all directions. The severity of ophthalmoplegia increased with duration of the illness in a signifi- 
cant manner $(p<0.01)$. The eyes were prominent with some eyelid retraction in $39 \%$ of cases. This and the ophthalmoplegia were responsible for the staring appearance. Nystagmus, horizontal and/or vertical, was present in 66 patients $(80.5 \%)$. Diplopia was a symptom in $52.4 \%$ of cases. In some patients, diplopia preceded other manifestations of the disease by many years. Altered vibratory sense was present in 65 patients (79.3\%) and its severity was clearly related to duration of the disease $(\mathrm{p}<0.01)$. Dysarthria $(90.4 \%)$ and dysphagia $(60.1 \%)$ were additional common findings.

Signs of extrapyramidal dysfunction were seldom observed. Dystonia was found in $20 \%$ of the patients with an earlier age of onset and seemed to persist regardless of the duration of the disease. Parkinsonian features were found in 6 patients, but were severe only in two. An increased tonus of the "lead pipe" type was often found in patients with long duration of disease and onset before age forty.

Some of these signs, mostly UMN signs, are related to the age of onset of the disease. However, the duration of the disease is the main variable responsible for the different degree of severity of most of the symptoms (Figures 1 and 2). Clinical manifestations are usually slowly progressive. As a consequence they follow a distribution as a continuum. This fact was clearly demonstrated when the patients were re-examined 2 years after the first observation (Table 2). Most of the findings, namely ataxia, UMN and peripheral signs, ophthalmoplegia, loss of vibratory sense, muscular atrophy, and fasciculations, had significantly deteriorated with the increased duration of the disease.

\section{Discussion}

Parkinsonian signs such as rigidity, sometimes accompanied by the cogwheel phenomenon, bradykinesia, and tremor have been described in dominant ataxias with variable frequency (Table 1). By contrast, other authors of larger series do not refer to these signs. ${ }^{7,15.36}$ We also found cogwheel rigidity to be rare. Confusion with paratonia or plastic rigidity of the lead pipe type may have contributed to conflicting reports. We would stress the close association of paratonia with increased reflexes and clonus, and its appearance in patients with early onset and long duration of the disease. Upper motor neuron signs were prominent when the disease started before age 30, became less apparent in the fourth decade, and no single case with spasticity or increased reflexes could be found when the disease appeared after age 50 .

In the patients originally described by Rosenberg et al, ${ }^{9}$ the disease started between the second to fourth decades (mean age of onset at 25 years). If we consider that UMN score is negatively related to age of onset, that UMN signs are associated in long-standing disease with paratonia and that dystonia was found in our series only when the disease started before age forty, it is not surprising that the main clinical features of the Joseph family were rigidity, spasticity and dystonia, as pointed out by Rosenberg et $\mathrm{al}^{9}$ and also in the family described by Healton et al ${ }^{15}$ with age of onset before 20 .

The degree of cerebellar dysfunction, as well as peripheral signs and loss of vibratory sense, are positively correlated with age of onset. It is not surprising that in members of the
Machado family described by Nakano et al, ${ }^{7}$ where the disease appeared after age forty, the main clinical findings were gait ataxia and depressed or absent tendon reflexes.

With respect to age of onset, the family reported by Romanul et al, 10 though small in size, lies between Joseph and Machado families. Clinically, some members were hyper- and others hyporeflexic; some had increased and others decreased muscle tone. In other words, this family exhibited signs intermediate between the Machado and Joseph families. Interestingly, the older cases of the Joseph and the younger cases of the Machado families fall in this intermediate area, as do the patients described by Romanul et al, 11 and Lima and Coutinho. ${ }^{14}$

To reconcile the apparent heterogeneity of the disease, Coutinho et al ${ }^{12,37}$ and Rosenberg et al ${ }^{13,38}$ proposed a subclassification consisting of 3 phenotypes. Although there are slight disagreements, type I seems to correspond to the symptom complex of the younger group (UMN signs, dystonia, mild or absent cerebellar dysfunction) and of long-standing cases (increased muscle tone of "lead pipe" type). Type II refers to the intermediate condition in which the less prominent UMN signs coexist with peripheral and cerebellar symptoms. Type III corresponds to the older group of patients in whom the cerebellar and peripheral features predominate. Indeed, as age of onset increases, the UMN signs become less prominent and dystonia and increased tone vanish (Figure 1). On the other hand, the cerebellar and peripheral signs become more prominent. As the variation of these signs seems to occur in a continuous fashion, ${ }^{36}$ the classification of individual patients is sometimes difficult or arbitrary, particularly within the same family. Furthermore, the symptoms and signs change as the disease progresses. Ataxia, as well as peripheral signs and loss of vibratory sense, become more prominent. Correlations with the duration of the disease are generally in agreement with data from a previous paper ${ }^{36}$ and confirmed in a follow-up study (Table 2). They argue against a rigid classification of types.

Ophthalmological manifestations were frequent in our patients. Diplopia was the first symptom in $10 \%$ of the total. The presence of ophthalmoplegia was independent of age of onset but become more marked as the disease progressed (Figure 2).

Fasciculations also became more prominent with the duration of the disease. However, as this finding also correlates with age of onset, it tends to coexist with high ataxia scores.

We submit that the disease will be better defined by understanding the variation and combination of the different clinical complexes than by rigid diagnostic criteria. If it is impossible to be certain that we are dealing with the same disease in the 28 families under study, we can at least say that the variation and combination of these signs are uniform considering age of onset and duration of the illness.

The nosological problem still persists, however. The individualization of the disease based on pathological criteria is not confirmed in each family of the series and, as can be appreciated in Table I, Machado-Joseph disease and OPCA share the same clinical picture. Moreover, even the dynamic definition of the disease that we propose seems inappropriate in the differential diagnosis between Machado-Joseph and OPCA: decreased reflexes and loss of vibratory sense related to duration of the disease have already been described in OPCA. ${ }^{21,39,41}$ 
We propose, therefore, that the term "ataxic multisystem degenerations" proposed by Barbeau et al ${ }^{36}$ is appropriate when referring to the families of this study. The individualization between Machado-Joseph disease and OPCA should be confined to cases with histopathological confirmation.

\section{ACKNOWLEDGEMENT}

The authors are thankful to Drs. P. Ferreira and M. Viegas for statistical assistance.

\section{REFERENCES}

1. Greenfield J. In: The spino-cerebellar degenerations. Oxford: Blackwell, 1954

2. Konigsmark B, Weiner L. The olivopontocerebellar atrophies: a review. Medicine 1970; 49: 227-241.

3. Weiner LP, Konigsmark BW, Stoll J, et al. Hereditary olivopontocerebellar atrophy with retinal degeneration. Report of family through six generations. Arch Neurol 1967; 16: 364-374.

4. Harding A. The clinical features and classification of the late onset autosomal dominant cerebellar ataxias. A study of 11 families, including descendents of "The Drew family of Walworth". Brain 1982; 105: 1-28.

5. Berciano J. Olivopontocerebellar atrophy: a review of 117 cases. J Neurol Sci 1982; 53: 253-272.

6. Koeppen A, Goedde H, Hirth L, et al. Adult-onset hereditary ataxia in Scotland. Arch Neurol 1977; 34:611-618.

7. Nakano K, Dawson D, Spence A. A hereditary ataxia in Portuguese emigrants to Massachusetts. Neurology 1972; 22: 49-55.

8. Woods B, Schaumburg H. Nigro-spino-dental degeneration with nuclear ophthalmoplegia. J Neurol Sci 1972; 17: 149-166.

9. Rosenberg R, Nyhan W, Bay C, et al. Autosomal dominant striatonigral degeneration: a clinical, pathologic and biochemical study of a new genetic disorder. Neurology 1976; 26: 703-714.

10. Romanul F, Fowler H, Radvany J, et al. Azorean disease of the nervous system. New Engl J Med 1977; 296: 1505-1508.

11. Romanul F, Radvany J, Fowler H, et al. Azorean disease of the nervous system: report of six additional families. Trans Amer Neurol Assoc 1978; 103: 269-273.

12. Coutinho P, Andrade C. Autosomal dominant system degeneration in Portuguese families of the Azores Islands. Neurology 1978; 28: 703-709.

13. Rosenberg R, Nyhan W, Coutinho P, et al. Joseph's disease: an autosomal dominant neurological disease in the Portuguese of the United States and the Azores Islands. In: Kark P, Rosenberg R and Schut L, eds. Adv Neurol New York: Raven Press 1978; 21: $32-57$.

14. Lima L, Coutinho P. Clinical criteria for diagnosis of MachadoJoseph disease: report of a non-Azorean Portuguese family. Neurology 1980; 30: 319-322.

15. Healton E, Brust J, Kerr D, et al. Presumably Azorean disease in a presumably non Portuguese family. Neurology 1980; 30: 1084 1089.

16. Goto I, Tobimatsus, Ohta $\mathrm{M}$, et al. Dentatorubro-pallido-luysian degeneration: Clinical, neuro-ophthalmologic, biochemical and pathologic studies of autosomal dominant form. Neurology 1982; 32: 1395-1399.
17. Chazol G, Knopp K, Barbeau A, et al. La maladie de Joseph (2 cas dans une famille française). Rev Neurol (Paris) 1983; 139-228.

18. Cooper J, Nakada T, Knight R, et al. Autosomal dominant motor system degeneration in a black family. Ann Neurol 1983; 14: 585-587.

19. Brown S. On hereditary ataxy, with a series of twenty-one cases. Brain 1982; 15: 250-282.

20. Ferguson F, Critchley M. A clinical study of an heredo-familial disease resembling disseminated sclerosis. Brain 1972; 52: $203-$ 225.

21. Schut J. Hereditary ataxia: clinical study through six generations. Arch Neurol Psychiat 1950; 63: 535-568.

22. Boller F, Segarra J. Spino-pontine degeneration. Europ Neurol 1969; 2: 356-373.

23. Pogacar $\mathrm{S}$, Ambler $\mathrm{M}$, Conklin $\mathrm{W}$, et al. Dominant spinopontine atrophy: report of two additional members of family W. Arch Neurol 1978; 35: 156-162.

24. Boudin G, Barbizet J, Le Henaff $M$. Hérédo-ataxie cérébelleuse avec amblyopie et paralysie de la verticalité du regard chez la mère et l'enfant. Rev Neurol (Paris) 1956; 87: 330-335

25. Bjork A, Lindblom U, Wadensten L. Retinal degeneration in hereditary ataxia. J Neurol Neurosurg Psychiatry 1956; 19: 186-193.

26. Jampel R, Okazaki H, Bernstein H. Ophthalmoplegia and retinal degeneration associated with spino-cerebellar ataxia. Arch Ophthalmol 1961; 66: 247-259.

27. Bergstedt M, Johansson S, Muller R. Hereditary spastic ataxia with central retinal degeneration and vestibular impairment. A clinical report on a family. Neurology 1962; 12: 124-132.

28. Carpenter S, Schumacher G. Familial infantile cerebellar atrophy associated with retinal degeneration. Arch Neurol 1966; 14: 8294.

29. Waggoner R, Lowenberg K. Arbor A, et al. Hereditary cerebellar ataxia. Report of a case and genetic study. Arch Neurol Psych 1938; 39: 570-586.

30. Weber F, Greenfield J. Cerebello-olivary degeneration: an example of heredo familial incidence. Brain 1942; 65: 220-231.

31. Chandler J, Bebin J. Hereditary cerebellar ataxia. Olivopontocerebellar type. Neurology 1956; 6: 187-197.

32. Taniguchi R, Konigsmark B. Dominant spino-pontine atrophy: report of a family through three generations. Brain 1971; 94 349-359.

33. Ishino $\mathrm{H}$, Sato $M$, Terão $A$, et al. Hereditary spastic ataxia: report of a family through four generations. Folia Psychiat et Neurol Japonica 1971; Vol 25, 4: 269-281.

34. Sachdev H, Forno L, Kane S. Joseph disease: a multisystem degenerative disorder of the nervous system. Neurology 1982;32: 192-195.

35. Pourcher E, Barbeau A. Field testing of an ataxia scoring and staging system. Can J Neurol Sci 1980; 7: 339-344.

36. Barbeau A, Roy M, Cunha L, et al. The natural history of Machado-Joseph disease. An analysis of 138 personally examined cases. Can J Neurol Sci 1984; 11: 510-525.

37. Coutinho P, Sequeiros J. Aspects cliniques, génétiques et pathologiques de la maladie de Machado-Joseph. J Génét Hum 1981; 29: 203-209.

38. Rosenberg R, Fowler H. Autosomal dominant motor system disease of the Portuguese: a review. Neurology 1981; 31: 11241126.

39. Pedersen L. Hereditary ataxia in a large Danish pedigree. Clin Genet 1980; 17: 385-393. 